\title{
DEVELOPMENT OF STANDARDS IN MUNICIPAL GOVERNMENT
}

\author{
By Henry Brù̀re, \\ Chamberlain, New York City.
}

To discuss broadly the development of standards in American city government would require complete consideration of the new temper and quality of civic administration throughout the country. In common use, the word "standard" connotes quality of conduct and character of service. "Standards of efficiency," "business standards," "standards of economy," are phrases now in frequent use in city government talk. They express vaguely, perhaps, but nevertheless suggestively, the new juxtaposition of ideas in reference to city government, and imply that there are positive tests available, if as yet unformulated, for measuring the quality of city government.

These phrases are to a large degree the product of the recent regeneration of American city government. Before commission government, bureaus of municipal research, and the city manager plan, there were no concepts of standards for city government except with regard to the virtue or morality of public officials. Tests applied to city activities were, therefore, negative rather than positive. Manifestations of effectiveness were not measured against an ideal of maximum effectiveness, but against the shades and shadows of conventional civic incompetence and corruption.

Standardization is a part of the process of creating objective tests for various municipal activities. The present development of standards in city government represents the efforts of the analysts of civic management as well as of civic administrators to develop efficient practices and to establish tests for measuring the effectiveness of city work.

Standardization may mean any one or all of the following:

1. The application of accumulated and analyzed experience in respect of the past performances of specific services or functions to the future or current performances of such services or functions. 
2. The establishment of a scale of merit for measuring values in work, services, supplies, materials, etc.

3. Devising structures or parts of structures so that they may be best adapted to their prospective uses and susceptible of ready reproduction, replacement or interchange.

4. The development of exemplary processes for the performance of work of a specific character or for classes of work, or for general application where like work is performed under like or closely similar conditions, or for gauging the efficiency of methods already in use.

In each of the foregoing relations standards may be objectively represented in the form of specifications, procedures, physical product or work methods. They are of no value unless they can be so objectively expressed and thus made to serve as a denominator for measuring cognate services or products by the public (consumers or citizens), by administrators, and by those who perform or control the work of administrators.

In government, standards are of practical value in promoting efficiency: (1) as a basis for measuring needs with respect to which services are to be performed; (2) for determining appropriations of funds by means of which services are to be performed; (3) for guiding administrators in performing such services; (4) for establishing a scale of compensation equated to the value of work performed; (5) for equating values with prices paid for supplies; (6) for guiding the selection of personnel, materials, supplies and equipment in accordance with the requirements of prospective service or use; (7) for regulating the routine performance of duties by the various integral parts of the organization; (8) for providing in various relations the means of common understanding between public, officials, administrators, appropriating bodies, etc.

Standardization means the formulation of definite concepts with respect to the elements of administration as opposed to vague generalized impressions.

Standardization provides a common language for the discussion of the problems of a specific business, both as between the public (citizens, consumers or stockholders) and administrator, and as between administrators.

The method of standardization varies with the nature of the problem under consideration. As between the application of the 
principle of standardization to public and private business, there is this fundamental difference: In private business there has been developed a body of recorded information respecting processes, organization, etc., acquiring somewhat the character of a science, as in banking. This recorded information is generally lacking in government, and if it were present would be of little value because of the low order of effectiveness of past governmental services. Standardization in government is, therefore, empirical, except in so far as experience and consequent method devised in private enterprise are applicable to governmental functions.

In many fields of private administration, standards have evolved gradually during a long period of effort to conduct the particular enterprise with maximum efficiency. In government, the desire for effectiveness on the part of officials, and the ability of the public to enforce its demands for efficiency, are of such recent origin, that in order to bring government practices up to best attainable levels, it has been necessary to undertake the conscious formulation of standards.

It will be clear, of course, that the methods employed in developing standards in city government are in large degree applicable to private business as well, because the methods of private business are susceptible to improvement through study, analysis, precise formulation, etc. Thus, compensation in private business is generally as unstandardized as in public business, so far as salaries are concerned. In many fields of private enterprise prices for labor are wholly devoid of standardization, even in the same industry, because subjective tests, generally in the form of haggling, are employed in fixing the compensation rather than objective tests in a form calculated to ascertain value of services performed, living requirements, etc. In many respects, obvious to students of administration, standardization is as necessary in private business as in public business.

Because of the extensive character of New York City's program in standardization, as well as because of the similarity of problems of administration in government to those existing in private enterprise, New York's exceptional present efforts to develop standards will be of value not only to other municipalities, but in many respects to private enterprise.

A prefatory word may be said regarding the origin of standard- 
ization in cities. The first attempt to standardization, so far as I know, was in reference to specifications for paving. Paving construction in New York and in other American cities was troublesome for many years, because of the lack of technical information on the part of city representatives respecting the nature of paving. Contractors' guarantees were relied on to ensure satisfactory pavements, with the result that throughout the city there developed the greatest inequality in paving conditions resulting in public concern regarding the use of vast appropriations for paving purposes.

Standard specifications were evolved, first to control the use of funds appropriated to different divisions of the government for paving, and subsequently to formulate the technical experience of the city, supplementing or opposed to the technical experience of engineers employed by contractors and ensuring for the city a pavement of suitable character. Through the provision of uniform specifications for paving, the appropriating authorities of the city set up the first objective use test for measuring appropriations. Similarly, the board of education through its architectural department had developed a standard type of school building, not so much to control the use of funds, as to facilitate the construction of school buildings by utilizing the accumulated experience of the department in planning a type of building best adapted for New York City's school purposes.

It was, however, rather as an incident to the control of appropriations made by the fiscal authorities, than as a means of planning and directing administrative activities by the executive branch of the city government, that the process of standardization developed in New York. As now worked out it includes the following major lines of activity:

Standardization of supplies, materials and equipment.

Standardization of salaries.

Standardization of accounting, payroll preparation, voucher processes, office practice, reporting, etc.

Standardization of purchasing practice.

Standardization of work methods.

Standardization of principles of management. 


\section{Standardization of Supplies Specifications}

Standardization of supplies specifications promotes efficiency from three standpoints:

1. From the standpoint of the user of supplies.

2. From the standpoint of the vendor.

3. From the standpoint of those responsible for the appropriation and administration of funds.

The work of supplies standardization has been in progress in New York since 1910. It has proceeded slowly for several reasons, the most conspicuous being the absence of precedent and the inadequacy of the machinery provided for the development of standards. The task, however, has been one of prodigious proportions involving the analysis and description of some 22,000 articles in current use in various city departments, and annual expenditures of some $\$ 15,000,000$.

To prepare standard specifications for supplies, the following steps are necessary: First, the use to which the supply is put must be determined, then, whether the particular character of supply currently requisitioned is best adapted for the purposes served. These being determined, the essential qualities and characteristic of the supply must be ascertained either by the advice of practical experts or by technical analysis. The results of this advice or analysis must then be formulated into terms which are understandable in the trade, susceptible of easy enforcement and permissive of competition among vendors. These steps having been taken there are available for the use of purchasing agents, specifications calling for carefully selected articles designed to satisfy the use requirements of requisitioning departments.

In New York standardization of supplies has gradually developed the basis for an efficient central purchasing plan, making possible the consolidation of the requirements of a large number of different departments into joint contracts for purchase. Now, when forage, food supplies, such as meats, coffee, canned goods, etc., coal chemicals, soap, etc., are requisitioned by any one of ten or fifteen consuming departments of the city government, the requisition expresses a quickly understood requirement and leads to a purchase which provides for every branch of the city government having like needs a supply of like character. Before standardization, a requisition for coal had a different meaning in 
every one of the thirty-two departments consuming coal in the city. A requisition for soap meant only what the dealer found it profitable to have it mean. It is inconceivable that supplies may be purchased efficiently without standardization. Neither can they be efficiently used or intelligently desired unless supply requirements of the using institution have been subjected to the processes now implied by the term "standardization."

\section{Standardization of Salaries}

In government, wages and salaries represent the principal part of the annual outlay. Unscientific determination of personal service compensation rates has been a principal cause of municipal inefficiency. New York, Chicago, Milwaukee, Pittsburgh and one or two other cities have recently undertaken to re-order salary schedules on the basis of a standard classification of positions and the adjustment of rates to the character of work and its relative value in the field of city employment. The procedure involves, first, an analysis of work actually performed by units or groups in an organization, consideration of the feasibility of readjusting work so as to make existing compensation or desirable compensation more appropriate to the position, or adjustment of compensation up or down to conform with rates paid for similar service elsewhere in the government or in private employment.

In practice, the application of a standard plan of compensation to an existing schedule is likely to involve either the ungrateful task of reducing salaries, or the alternative of waiting for vacancies to readjust compensation for the appointment of fresh incumbents. Standards may be applied with ease, of course, to new positions as they are created, and wherever an increase of compensation will result by reason of existing underpayment or underassignment of duties.

New York City, through its bureau of standards, has prepared a plan of promotion, a standard classification and uniform rates for the several grades in the fifteen primary divisions of city service. ${ }^{1}$

1 These divisions are as follows:

Executive

Legislative

Judicial

Professional

Investigational
Social and Educational

Sub-Professional

Inspectional

Clerical

Custodial
Police

Institutional

Street Cleaning

Skilled Trades

Labor 
This work is perhaps the first comprehensive attempt made to determine a scheme of compensation based upon the value of work performed, its relation to other grades and classes of work required by the institution, and the considerations of standards and cost of living, special qualification required, opportunities for advancement, provision of superannuation pensions, etc. The New York work furnishes a basis for considering compensation in all fields of activity, public and private, and is the first attempt to supplant the haphazard, bargaining, accidental determination of salary rates with a definitely formulated plan of compensation based on such principles as experience evolved from employing and paying upwards of 80,000 employees has suggested.

The field of compensation standardization is so broad that one is not safe in generalizing on a brief statement of the elements of the problem. It may be said at this time, however, that a rational plan of compensation is the first requirement of efficient organization, and indispensable to just and successful management of a large body of employees. The field of salaries and wages furnishes one of the most inviting opportunities for constructive effort, not only in government but also in industries and mercantile activity.

One is inclined to picture an institution ordered by some arbitrary process of regimentation when considering the complete application of standards to administration. The fact is, however, that an essential element of standardization is the recognition of the necessity of divergencies from the standard. This is true in regard to compensation, forms of organization and even details of procedure, for no two organizations can be made identical unless the elements involved in the organizations are identical. In city government this rarely happens. But there are certain elements of routine administrative procedure which may be patterned on a common model under varying forms of organization. Thus, there have been installed in New York City standard accounting practices in the several departments, uniform methods of payroll preparation, standard filing systems, methods for handling correspondence, etc. These routines, with modifications in detail, may be applied as an aid to efficient administration throughout a city government. So much has been said of this aspect of the problem of ordering practice to conform to the formulation of comparative experience, that I need only refer to it in passing. 
Least has been done in the most important field of activity to which standards may be applied, namely, the actual processes of operation themselves. In 1913 the board of estimate and apportionment in New York established a division of efficiency to make detailed examinations of methods employed in the conduct of public business, and by tests to establish a standard routine for the performance of work. Studies were made in the borough of Richmond of various public works activities, and as a result of long experiments in planning work, organizing gangs, arranging for delivery of material, devising records to govern the performance of work, the formulation of specific instructions, etc., standard routines were evolved. These have as yet failed of application to other sections of the city where similar work is done, because of decentralized responsibility and the persistence of a spirit of individual freedom in the management of public departments, which is one of the principal embarrassments to efficient municipal administration.

Similar analyses of work problems and methods are now in progress in the department of street cleaning. An average, typical section of the city has been selected for the development of model methods for general application. Here, as in other similar problems, observation, analysis, recording, comparison, testing and measurement of results by a standard or ideal established as a goal, are the methods pursued in evolving a standard, efficient practice.

It is proposed to apply the same method to every branch of city activity. This has already been done in numerous fields. Indeed, the process of analysis has somewhat outrun the actual application of the results of analysis by administrators. But not until New York obtains a greater degree of centralized authority in administration so much needed, will it be able to apply standards to its multifarious fields of activity. Theoretically, the opportunity for standardization runs from end to end of city government. There is first the study of the field of municipal activity, to learn what are the problems to be solved and what service standards are to be observed in solving them. Thus, it is not enough to standardize methods of street cleaning, a standard of cleanliness must be determined as a prerequisite. In determining a standard of cleanliness, it is necessary to consider health and comfort requirements, cost 
limitations, efficiency in equipment, limitations imposed by traffic, habits of street users, or residents, etc.

Efficient administration involves as a continuing process the formulation of standards and their revision with changing conditions. Gradually, in this way, a body of experience and method will be developed under which a city government may be conducted up to the level of efficiency which the knowledge and capacity obtained from years of analytical conduct of the activities of government will have produced. New York is fairly well launched on a program of standardization. It is formulating principles of administration by which to test its standards. More and more it is recognizing that no limitations may be placed upon the effectiveness of city service except the changing limitations of human knowledge and ability. The apologist has played his part and exhausted the array of excuses which have heretofore been accepted in lieu of efficient municipal service. Standardization is both a challenge to city administrators and the means by which they are able to answer to demands for greater effectiveness in city management. 